\title{
(Re)Ler o manifesto “A Pedagogy of Multiliteracies: Designing Social Futures" hoje
}

\author{
Ricardo Tavares Martins*
}

Resumo: O manifesto A Pedagogy of Multiliteracies: Designing Social Futures completa hoje, em 2021, 25 anos de sua publicação. Objetivamos aqui fazer uma (re)leitura do manifesto tão minuciosa e atenta quanto possível em tempos e lugares outros diferentes daqueles nos quais se deu sua concepção e, para tanto, voltamos ao texto seminal (1996) no seu original em língua inglesa, apoiando-nos também em traduções e referencial teórico cuja pedagogia dos multiletramentos é o cerne. Concluímos pela necessidade de constante (re)leitura do manifesto, pois cada (re)leitura está inserida em contextos sociais e culturais mutáveis ao longo do tempo. Palavras-chave: Multiletramentos. Pedagogia. Design.

\begin{abstract}
The manifesto A Pedagogy of Multiliteracies: Designing Social Futures celebrates today, in 2021, 25 years of its publication. We aim here to do a (re)reading of the manifesto as thorough and attentive as possible in other times and places different from the ones in which happened its conception and for that we return to the seminal text (1996) in its original version in English, also relying on translations and theoretical framework whose pedagogy of multiliteracies is the core. We concluded that there is a need for constant (re)reading of the manifesto because each (re)reading is inserted in social and cultural contexts that are changeable over time.
\end{abstract}

Keywords: Multiliteracies. Pedagogy. Design.

Resumen: El manifiesto Una Pedagogía de la Multiliteracidad: Diseñando Futuros Sociales celebra hoy, en 2021, 25 años de su publicación. Nuestro objetivo aquí es hacer una (re)lectura del manifiesto lo más completa y atenta posible en otros tiempos y lugares distintos de los que se fue concebido y por lo tanto volvemos al texto seminal (1996) en su original en Inglés, apoyándonos también en traducciones y marco teórico cuya pedagogía de la multiliteracidad es el núcleo. Concluimos que existe la necesidad de una (re)lectura constante del manifiesto, ya que cada (re)lectura se inserta en contextos sociales y culturales que son cambiantes a lo largo del tiempo.

Palabras claves: Multiliteracidad. Pedagogía. Design.

\footnotetext{
* Professor do Instituto Federal de Educação, Ciência e Tecnologia do Sertão Pernambucano (IF SertãoPE) e mestrando pelo Programa de Pós-Graduação em Letras da Universidade Federal de Pernambuco (UFPE). http://orcid.org/oooo-0002-5276-2678 / E-mail: ricardotavares_15@yahoo.com.br
}

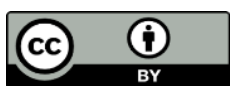




\section{Introdução}

Vinte e cinco anos se passaram desde a publicação do manifesto A Pedagogy of Multiliteracies: Designing Social Futures, e, após quase três décadas, as ideias defendidas pelo manifesto ainda ecoam nos dias de hoje.

Nosso objetivo aqui é fazer uma (re)leitura do manifesto, "tão minuciosa e atenta quanto possível” (RIBEIRO, 2020, p. o1) após 25 anos de sua publicação em tempos e espaços diferentes daqueles nos quais se deu sua produção e, para tanto, recorremos ao manifesto no seu original em língua inglesa (1996) e também a traduções (GRUPO NOVA LONDRES, 2021; CAZDEN et al., 2021) e referencial teórico que tomam a pedagogia dos multiletramentos como norteadora de pesquisas e práticas docentes (COPE; KALANTZIS, 2009, 2012; COPE; KALANTZIS; PINHEIRO, 2020; TILIO, 2021; ROJO; MOURA, 2012; RIBEIRO, 2020; HISSA; SOUSA, 2020; PINHEIRO, 2016, 2021).

Ao fazermos uma (re)leitura em tempos e lugares outros, tentamos contextualizar ao máximo possível nosso texto ao inserir exemplos, questionamentos e críticas que contribuam para o diálogo com a pedagogia dos multiletramentos, 25 anos após sua concepção.

\section{O manifesto}

Como um dos nossos objetivos aqui é fazer uma (re)leitura minuciosa e atenta do manifesto, e como há apenas pouco tempo surgiram traduções do texto seminal (1996), dedicamos este tópico a essa (re)leitura minuciosa e atenta.

O manifesto A Pedagogy of Multiliteracies: Designing Social Futures foi idealizado em 1994, em Nova Londres, Estados Unidos, por um grupo de dez estudiosos preocupados com as questões sociais que se desenhavam no final do século passado e apontavam para seu recrudescimento no século seguinte: as diversidades culturais e 
linguísticas, bem como as crescentes desigualdades. Dois anos depois, em 1996, o manifesto foi publicado na Harvard Educational Review e, para além de um manifesto programático, apresentou uma proposta de Projeto Internacional de Multiletramentos.

O entendimento que o The New London Group (doravante NLG), como ficou conhecido o grupo de estudiosos que escreveu o manifesto, tinha já naquela época sobre educação, era a de que a educação possui uma missão com propósito fundamental de "garantir que todos os estudantes se beneficiem da aprendizagem de maneira que os permita participar de forma completa da vida pública, comunitária e econômica."1 (THE NEW LONDON GROUP, 1996, p. 6o, tradução nossa).

O NLG percebeu, no entanto, que esse não era o ideal de educação que vinha se desenhando. O que foi observado pelo NLG foi uma pedagogia ainda bastante pautada no ler e escrever no caderno as formas padrões da língua nacional, no caso o Inglês. $\mathrm{O}$ que estava se inscrevendo na sociedade dos anos finais da década de 90 e início dos anos 2000 iria exigir uma pedagogia para além do ler e escrever no caderno as formas padrões da língua, por isso os objetivos do manifesto jaziam em destacar a necessidade de letramento para uma sociedade cada vez mais diversa cultural e linguisticamente, e interligada pela globalização através da pluralidade de textos que circulam, levando em consideração que essas formas textuais estão associadas com as tecnologias da informação e multimídia.

Levando em consideração o que foi supracitado, outras questões norteavam o NLG: que educação é apropriada para mulheres, povos indígenas, imigrantes que não falam a língua nacional, falantes de dialetos não padronizados (ou seja, para variantes não valorizadas da língua)? O que é apropriado para questões de diversidade local, mas de conexão global? O que é apropriado para comunidades partidas e para uma sociedade cada vez mais excludente? O que ensinar e como ensinar? Então, a partir desses questionamentos, o NLG cunhou o termo multiletramentos e sua definição (THE NEW LONDON GROUP, 1996, p. 63-64, tradução nossa):

\footnotetext{
${ }^{1}$ No original: "to ensure that all students benefit from learning in ways that allow them to participate fully in public, community, and economic life."
} 
Decidimos que os resultados de nossas discussões poderiam ser encapsulados em uma palavra - multiletramentos - uma palavra que escolhemos para descrever dois argumentos importantes que podemos ter com a ordem emergente cultural, institucional e global a multiplicidade de canais de comunicação e mídia, e com a crescente saliência das diversidades cultural e linguística. A noção de multiletramentos suplementa a tradicional pedagogia de letramento ao abordar esses dois aspectos relacionados com a multiplicidade textual. O que podemos chamar de "mero letramento" permanece centrado apenas na língua, e normalmente numa forma nacional singular de língua que é concebida como um sistema estável baseado em regras tais como dominar a correspondência letra-som. Isso é baseado no pressuposto de que podemos discernir e descrever o uso correto. Esse tipo de visão da língua se traduzirá caracteristicamente em um tipo de pedagogia mais ou menos autoritária. Uma pedagogia dos multiletramentos, por outro lado, foca em modos de representação muito mais amplos do que a língua em si mesma. Isso difere de acordo com a cultura e o contexto e tem efeitos cognitivo, cultural e social específicos. Em alguns contextos culturais - em uma comunidade aborígene ou um ambiente multimídia, por exemplo - o modo visual de representação pode ser muito mais poderoso e relacionado à língua do que o "mero letramento" jamais poderá ser capaz de permitir. Multiletramentos também criam um tipo de pedagogia diferente, na qual a língua e outros modos de significação são recursos representacionais dinâmicos, constantemente sendo refeitos pelos seus usuários enquanto trabalham para alcançar seus vários propósitos

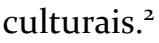

Após cunharem o termo multiletramentos, outros dois argumentos chamaram a atenção do NLG: 1) o aumento, a multiplicidade e a integração de modos de criar significados nos quais o textual está relacionado ao audiovisual, espacial, comportamental, etc.; 2) diferenças linguísticas e culturais na pragmática das vidas laboral, cívica e privada utilizando múltiplas linguagens e padrões de comunicação.

\footnotetext{
${ }^{2}$ No original: "We decided that the outcomes of our discussions could be encapsulated in one word multiliteracies - a word we chose to describe two important arguments we might have with the emerging cultural, institutional, and global order: the multiplicity of communications channels and media, and the increasing saliency of cultural and linguistic diversity. The notion of multiliteracies supplements traditional literacy pedagogy by addressing these two related aspects of textual multiplicity. What we might term 'mere literacy' remains centered on language only, and usually on a singular national form of language at that, which is conceived as a stable system based on rules such as mastering sound-letter correspondence. This is based on the assumption that we can discern and describe correct usage. Such a view of language will characteristically translate into a more or less authoritarian kind of pedagogy. A pedagogy of multiliteracies, by contrast, focuses on modes of representation much broader than language alone. These differ according to culture and context, and have specific cognitive, cultural, and social effects. In some cultural contexts - in an Aboriginal community or in a multimedia environment, for instance - the visual mode of representation may be much more powerful and closely related to language than 'mere literacy' would ever be able to allow. Multiliteracies also creates a different kind of pedagogy, one in which language and other modes of meaning are dynamic representational resources, constantly being remade by their users as they work to achieve their various cultural purposes."
} 
Assim, o NLG convida alunos e professores a assumirem papéis nessa sociedade de novas exigências como alguns dos responsáveis pelos futuros sociais.

Então, sendo alunos e professores alguns dos responsáveis pelos futuros sociais, precisam assumir funções nos aspectos laborais, públicos (cívicos) e privados da vida e, para tanto, devem integrar uma pedagogia dos multiletramentos, pois, como apregoa o NLG, criar significado nessa sociedade é criar futuros sociais (THE NEW LONDON GROUP, 1996).

As práticas inseridas na pedagogia dos multiletramentos giram em torno do termo Design e, para tanto, o NLG elenca seis Designs que são importantes no processo de criação de significados: linguístico, audiovisual, gestual, espacial e multimodal, sugerindo quatro componentes para integrar a pedagogia dos multiletramentos: 1) Prática Situada (Situated Practice), baseada na experiência de criação de significado nos aspectos reais da vida; 2) Instrução Explícita (Overt Instruction), através da qual os estudantes desenvolvem uma metalinguagem do Design; 3) Enquadramento Crítico (Critical Framing), que interpreta o contexto social e o propósito dos Designs de significado; 4) Prática Transformada (Transformed Practice), na qual os estudantes, como criadores de significados, se tornam criadores de futuros sociais.

Os Designs e os componentes propostos pela pedagogia dos multiletramentos são os responsáveis por desenvolver a autonomia dos estudantes para atuarem em três domínios da vida social: laboral, público (cívico) e privado que veremos a seguir com mais detalhes.

\subsection{Os domínios da vida social}

O primeiro dos domínios se refere ao mundo do trabalho. O manifesto demonstra sua preocupação em relação ao mundo capitalista do trabalho que passa a exigir ações individualizadas de seus trabalhadores, ao mesmo tempo em que exige um trabalhador mais conectado com o mundo globalizado. Esse trabalhador conectado deve ser capaz de atuar em colaboração com os outros numa postura de "pós-fordismo" e "capitalismo 
rápido", nos quais os trabalhadores não são meros reprodutores de ações, mas integram um time e assumem valores das empresas para as quais trabalham. E juntamente com esse novo mundo do trabalho surge uma nova língua. Assim, trabalhadores precisam interagir com máquinas e suas telas e lidar com textos que circulam nesses ambientes, assumindo papéis de interlocutores.

Contudo, os autores do manifesto também deixam clara a preocupação de como o capitalismo pode fazer exigências preocupantes, ser bastante excludente e usar dos discursos pedagógicos veiculados no manifesto para um contexto orientado ao mercado. Podemos citar o caso da língua inglesa, por exemplo, como língua internacional de comunicação e dos negócios, sendo exigido um tipo específico de Inglês que possa representar a hegemonia de um país ou povo específico. Apesar de expressar essa preocupação, o manifesto fecha esse tópico sobre o mundo do trabalho de forma otimista (THE NEW LONDON GROUP, 1996, p. 67-68, tradução nossa):

Paradoxalmente, a nova eficiência requer novos sistemas que consigam motivar as pessoas podendo isso ser a base para um pluralismo democrático no ambiente de trabalho e além. No domínio do trabalho, temos chamado essa possibilidade utópica de diversidade produtiva com a ideia de que o que parece ser um problema - a multiplicidade de culturas, experiências, formas de criar significados, e formas de pensar - pode ser aproveitado como habilidade (Cope \& Kalantzis, 1995). Comunicação intercultural e o diálogo negociado de diferentes línguas e discursos podem ser uma base para a participação, acesso e criatividade do trabalhador, para a formação de redes localmente sensitivas e globalmente extensivas que relacionam de forma próxima organizações a seus clientes e fornecedores, e estruturas de motivações nas quais as pessoas sentem que suas experiências e conhecimentos diferentes são genuinamente valorizados. ${ }^{3}$

O segundo domínio diz respeito à vida pública. Esse domínio vem sofrendo constantes mudanças, especialmente após a Guerra Fria, quando escolas e universidades

\footnotetext{
${ }^{3}$ No original: "Paradoxically, the new efficiency requires new systems of getting people motivated that might be the basis for a democratic pluralism in the workplace and beyond. In the realm of work, we have called this utopian possibility productive diversity, the idea that what seems to be a problem - the multiplicity of cultures, experiences, ways of making meaning, and ways of thinking - can be harnessed as an asset (Cope \& Kalantzis, 1995). Cross-cultural communication and the negotiated dialogue of different languages and discourses can be a basis for worker participation, access, and creativity, for the formation of locally sensitive and globally extensive networks that closely relate organizations to their clients or suppliers, and structures of motivation in which people feel that their different backgrounds and experiences are genuinely valued."
} 
passaram a responder à lógica do mercado capitalista em governos cada vez mais liberais economicamente.

Quando se trata da língua, a postura também sofreu mudanças. No velho mundo, termo usado pelo manifesto para acentuar mudanças entre períodos, a educação usava a língua de forma a padronizá-la como nacional e demandar seu ensino em escolas em detrimento de variantes não padrão ou dialetos de comunidades menos favorecidas socioeconomicamente, além de impô-la a imigrantes e povos indígenas. No novo mundo, as diversidades linguísticas e culturais passam a ser vistas e é esperado que os sujeitos sejam capazes de negociar significados com falantes de outras línguas ou falantes de registros diferentes de sua própria língua, levando em conta características da linguagem que vão além do verbal. Então, nesse novo mundo, o Estado deve usar seu poder não para segregar, como no velho mundo, mas para fomentar a diversidade, como deixa claro o manifesto (THE NEW LONDON GROUP, 1996, p. 69, tradução nossa):

Os Estados devem ser fortes novamente, mas não para impor padrões: devem ser fortes como árbitros neutros da diferença. Assim como também devem ser as escolas e deve ser a pedagogia do letramento. Essa é a base para uma sociabilidade coesa, uma nova civilidade na qual diferenças são usadas como um recurso produtivo e na qual diferenças são a norma. É a base para o senso do pós-nacionalismo de propósito comum que é agora essencial para uma ordem global pacífica e produtiva (Kalantzis \& Cope, 1993b). ${ }^{4}$

Uma vez que o Estado possibilite às escolas toda essa diversidade, podemos ter uma série de benefícios para a vida pública. A diversidade linguístico-cultural pode ser usada como recurso para fomentar noções de espaços cívicos e cidadania. Além disso, ao ser possível toda essa diversidade, também torna-se possível possibilitar o acesso dos alunos a habilidades metacognitivas e metalinguísticas ao serem expostos a ambientes de diversidade, além de saberem atuar nesses ambientes e refletir sobre eles.

O terceiro e último domínio é o domínio da vida privada. Nesse domínio cabem as características que individualizam os seres e os fazem diferentes e únicos mesmo que

\footnotetext{
${ }^{4}$ No original: "States must be strong again, but not to impose standards: they must be strong as neutral arbiters of difference. So must schools. And so must literacy pedagogy. This is the basis for a cohesive sociality, a new civility in which differences are used as a productive resource and in which differences are the norm. It is the basis for the postnationalist sense of common purpose that is now essential to a peaceful and productive global order (Kalantzis \& Cope, 1993b)."
} 
componham um grupo específico: gênero, etnia, orientação sexual, etc. Ainda de acordo com o manifesto, esse domínio pode soar um pouco contraditório, pois, ao passo que trata do privado, é invadido por meios de comunicação de massa, pela cultura de comódites globais, redes de comunicação e informação. Para exemplo dessa invasão do privado, o manifesto cita brinquedos, desenhos animados, vídeo games que invadem os lares de crianças num domínio considerado privado e junto com essa invasão pode vir uma linguagem carregada de valores.

Outro aspecto contraditório citado pelo manifesto recai sobre como temas da vida privada se tornam cada vez mais públicos, impulsionados pelo interesse midiático: vida sexual de celebridades, casos de abuso sexual infantil, violência doméstica, etc. A isto, o NLG chamou de “conversacionalização” da linguagem pública, alegando que ela nem sempre tem aspectos apenas negativos, pois abre discussão para temas de importância social também.

Tendo apresentado os domínios da vida social, outro aspecto importante destacado pelo NLG é o impacto de um domínio sobre o outro. O manifesto cita como a linguagem do ambiente privado muitas vezes é transportada para o mundo do trabalho. Assim, como exemplo, citamos como é comum que muitas empresas levem mensagens para seus clientes e empregados para se "sentirem em casa", mesmo estando no ambiente de trabalho, ou que o chefe diga a seus empregados que todos ali fazem parte de uma família.

Após a apresentação desses domínios da vida social moderna, o que se apresenta para a sociedade é o desafio de conviver com todos eles e lidar com o fato de que eles não possuem fronteiras bem definidas com um invadindo o(s) outro(s). Isso pode ser explicado através do avanço tecnológico, sobretudo das tecnologias de comunicação impulsionadas pela internet. Esse avanço tecnológico contribuiu para que os domínios se chocassem, mas também permitiu maior visibilidade e voz para que os constituintes desses domínios fomentassem a diversidade tão necessária e apregoada pelo manifesto. Um exemplo dessa questão citado pelo manifesto está na palavra "comunidade", a comunidade gay, a comunidade afrodescendente, etc., que, por mais que se tente pôr em um nicho um determinado grupo, não impede que seus membros façam parte de 
mais de uma comunidade, como podemos perceber no manifesto (THE NEW LONDON GROUP, 1996, p. 71, tradução nossa):

Como as pessoas são simultaneamente membros de múltiplos mundos de vida, então as suas identidades têm múltiplas camadas que estão numa complexa relação umas com as outras. Nenhuma pessoa é membro de apenas uma única comunidade. Em vez disso, são membros de múltiplas e sobrepostas comunidades - comunidades de trabalho, de interesse e afiliação, de etnia, identidade sexual, e assim por diante (Kalantzis, 1995). ${ }^{5}$

Após todo esse percurso teórico sobre as questões que compõem a sociedade, o manifesto indaga como se inscreve a escola nessa sociedade. Sem dúvida, a escola ocupa um lugar de importância social e uma função bastante específica, lugar e função que o manifesto também destaca.

\subsection{O papel da escola}

A escola ocupa um lugar de destaque no manifesto pela importância que possui para a pedagogia dos multiletramentos, além de ser espaço de veiculação de discursos, poder político e reconhecimento cultural: "elas fornecem acesso a um mundo do trabalho hierarquicamente ordenado. Formam cidadãos. Fornecem um suplemento para os discursos e atividades das comunidades e mundos de vida privados" ${ }^{6}$ (THE NEW LONDON GROUP, 1996, p. 72, tradução nossa).

Assim, a escola do velho mundo centrada numa homogeneidade utópica dos cidadãos preparava seus alunos para as situações de sempre nos diversos domínios, criando homogeneidades a partir das diferenças. A escola do novo mundo deve ser o oposto. Deve levar em consideração as subjetividades de seus alunos - interesses, intenções, compromissos, propósitos - ao invés de ignorá-las ou apagá-las, e o currículo

\footnotetext{
${ }^{5}$ No original: "As people are simultaneously members of multiple lifeworlds, so their identities have multiple layers that are in complex relation to each other. No person is a member of a singular community. Rather, they are members of multiple and overlapping communities-communities of work, of interest and affiliation, of ethnicity, of sexual identity, and so on. (Kalantzis, 1995)"

${ }^{6}$ No original: "They provide access to a hierarchically ordered world of work; they shape citizenries; they provide a supplement to the discourses and activities of communities and private lifeworlds."
} 
não pode deixar de atender a várias linguagens, discursos e registros e usar tudo isso como recurso para o ensino-aprendizagem. Assim, surge uma pedagogia que põe a diversidade no centro do processo educativo sem que seus partícipes tenham que apagar ou deixar de lado suas subjetividades.

No entanto, o NLG não foi ingênuo ao pensar que à escola caberia a responsabilidade total para a mudança social. Ela é, de fato, uma grande instância desse processo de mudança social, mas não é a única. Por isso, as práticas desenvolvidas pela pedagogia defendida no manifesto devem levar o aluno a situações/papéis com os quais terá que lidar. Sendo assim, a escola deve propor atividades que privilegiem as relações de colaboração, compromisso e envolvimento criativo, que trabalhem com o acesso e a aprendizagem das mídias de massa com vistas a centrar a educação num espaço cívico e comunidades diversas de aprendizes que também são diversos e aprenderão a viver e respeitar essa diversidade e a autonomia dos domínios sociais. Contudo, o NLG lembra também que "diferentes concepções de educação e sociedade levam a formas específicas de currículo e pedagogia, que por sua vez incorporam Designs para futuros sociais"7 (THE NEW LONDON GROUP, 1996, p. 73, tradução nossa), e é por isso que se faz necessário o engajamento num diálogo crítico com os conceitos e termos desenvolvidos no manifesto caso o interesse seja tirar essas ideias do papel e levá-las à prática.

\subsection{A pedagogia dos multiletramentos}

A partir deste tópico, retomamos algumas questões postas no início deste texto, por serem questões importantes para o manifesto. A primeira questão se refere a "o quê" da pedagogia dos multiletramentos, ou seja, o que os alunos precisam aprender, e a segunda questão se refere ao "como" dessa pedagogia, ou seja, à gama de relacionamentos de aprendizagem.

\footnotetext{
${ }^{7}$ No original: "Different conceptions of education and society lead to very specific forms of curriculum and pedagogy, which in turn embody designs for social futures."
} 
Em “o quê" da pedagogia dos multiletramentos, veremos os Designs de significados, os Designs Disponíveis, o processo de Designing, o Redesigned, as dimensões do significado e os elementos do Design (linguístico e outros modos de significação). Enquanto que, no "como" da pedagogia dos multiletramentos, veremos seus quatro componentes constitutivos: Prática Situada, Instrução Explícita, Enquadramento Crítico e Prática Transformada.

\subsubsection{O “o quê" da pedagogia dos multiletramentos}

Em relação à primeira questão, ou seja, "o quê" os alunos precisam aprender, o NLG propôs uma metalinguagem de multiletramentos baseada no conceito de Design. Para o NLG, o termo Design se tornou central, tanto para o mundo do trabalho quanto para ambientes educacionais na contemporaneidade.

Nesse ambiente educacional contemporâneo, professores são vistos como Designers dos ambientes e dos processos de aprendizagem e não como chefes ditando o que alunos devem pensar/fazer. Essa noção de Design leva a uma ideia de que é necessário que educadores estejam sempre (re)desenhando suas práticas e também à ideia de que aprendizagem e produtividade são resultados de Designs de sistemas complexos de pessoas, ambientes, tecnologias, crenças e textos. Além disso, o termo Design foi escolhido pelo NLG para descrever as formas de significado porque, de acordo com os integrantes do grupo, esse termo é livre de associações negativas, como é, por exemplo, o termo "gramática" por parte de professores. Nas palavras do NLG (1996, p. 73-74, tradução nossa):

É um conceito suficientemente rico para fundamentar um currículo e uma pedagogia de língua. O termo também possui uma feliz ambiguidade: ele pode identificar a estrutura organizacional (ou morfologia) de produtos ou o processo de Designing. Expressões como "o design do carro" ou "o design do texto" podem ter os seguintes significados: a forma que ele é - ou foi desenhado ou o processo de desenhá-lo. ${ }^{8}$

\footnotetext{
${ }^{8}$ No original: "It is a sufficiently rich concept upon which to found a language curriculum and pedagogy. The term also has a felicitous ambiguity: it can identify either the organizational structure (or 
Assim, o NLG propõe tratar qualquer atividade semiótica, incluindo usar a língua para produzir e consumir textos, como uma questão de Design envolvendo três elementos: os Designs Disponíveis, ou seja, o que há na língua disponível para uso, o Designing como o processo de criação de significados e o Redesigned, que seria o produto: "Juntos esses três elementos enfatizam que a criação/produção de significados é um processo ativo e dinâmico e não algo governado por regras estáticas." ${ }^{9}$ (THE NEW LONDON GROUP, 1996, p. 74, tradução nossa).

Os Designs disponíveis incluem as gramáticas de vários sistemas semióticos - das línguas, mas também de outros sistemas semióticos tais como os ligados a imagens e gestos - além de incluírem também as "ordens do discurso"10 (FAIRCLOUGH, 1995 apud THE NEW LONDON GROUP, 1996, p. 74, tradução nossa, destaques do original):

\begin{abstract}
Uma ordem do discurso é o conjunto estruturado de convenções associadas com a atividade semiótica (incluindo o uso da língua) em um dado espaço social uma sociedade particular ou uma instituição particular tal como uma escola ou um local de trabalho, ou espaços mais vagamente estruturados de vida normal encapsulada na noção de diferentes mundos de vida. Uma ordem do discurso é uma matriz de discursos socialmente produzida, entrelaçando e dinamicamente interagindo. É uma configuração particular dos elementos do Design. Uma ordem do discurso pode ser vista como uma configuração de tais elementos. Ela pode incluir uma mistura de diferentes sistemas semióticos sistemas semióticos visual e auricular em combinação com a língua constituem a ordem do discurso da TV, por exemplo. Pode envolver as gramáticas de várias línguas - as ordens do discurso de várias escolas, por exemplo."
\end{abstract}

morphology) of products, or the process of designing. Expressions like 'the design of the car', or 'the design of the text', can have either sense: the way it is - has been - designed, or the process of designing it."

${ }^{9}$ No original: "Together these three elements emphasize the fact that meaning-making is an active and dynamic process, and not something governed by static rules."

${ }^{10} \mathrm{O}$ conceito de discurso para o NLG é o mesmo usado por Norman Fairclough em sua Análise Crítica do Discurso, uma vez que Fairclough também assinou o manifesto como um dos membros. Para ele, o discurso é a utilização da linguagem como prática social e não apenas como prática individual. Quer dizer, o discurso é visto como uma maneira dos indivíduos agirem, interagirem e representarem o mundo, havendo uma implicação dialética entre o discurso e a estrutura social.

${ }^{11}$ No original: "An order of discourse is the structured set of conventions associated with semiotic activity (including use of language) in a given social space - a particular society, or a particular institution such as a school or a workplace, or more loosely structured spaces of ordinary life encapsulated in the notion of different lifeworlds. An order of discourse is a socially produced array of discourses, intermeshing and dynamically interacting. It is a particular configuration of Design elements. An order of discourse can be seen as a particular configuration of such elements. It may include a mixture of different semiotic systems - visual and aural semiotic systems in combination with language constitute the order of discourse of TV, for instance. It may involve the grammars of several languages - the orders of discourse of many schools, for example." 
Outra característica da ordem do discurso é que diferentes discursos se relacionam um(uns) com outro(s). Imaginemos os discursos científico e religioso, da lei e do crime, dentre tantos outros que em algum momento se cruzam. E, nessa questão, a escola não fica de fora, pois nela também circulam diversos discursos: discurso sobre ser professor, sobre ser aluno, etc., além do fato de que esses discursos são veiculados por diferentes pessoas; diferentes alunos de cores, raças, idades distintas e professores de disciplinas diferentes, da rede pública ou privada, jovem ou velho, etc.; assim “[...] diferentes tipos de pessoas se conectam através de discursos entrelaçados que constituem as ordens do discurso"12 (THE NEW LONDON GROUP, 1996, p. 75, tradução nossa).

Dentro das ordens do discurso, existem convenções particulares de Design Designs Disponíveis - que tomam a forma de discursos, estilos, gêneros, dialetos e vozes (THE NEW LONDON GROUP, 1996, p. 75, tradução nossa, destaques do original):

\begin{abstract}
Um discurso é uma configuração de conhecimento e suas formas habituais de expressão que representam um conjunto particular de interesses. Com o tempo, por exemplo, instituições produzem discursos - ou seja, suas configurações de conhecimento. Estilo é a configuração de todas as características semióticas de um texto no qual, por exemplo, a língua pode estar relacionada ao layout e imagens visuais. Gêneros são formas de texto ou de organização textual que surgem de configurações sociais particulares ou de relações particulares dos participantes numa interação. Eles refletem o propósito dos participantes em uma interação específica. Em uma entrevista, por exemplo, o entrevistador quer algo, o entrevistado quer algo mais e o gênero entrevista reflete isso. Dialetos podem estar relacionados à idade ou região geográfica. Voz é mais individual e pessoal, incluindo, claro, muitos fatores discursivos e genéricos. ${ }^{13}$
\end{abstract}

As convenções supracitadas são necessárias para enfatizar que, no Designing de textos e interações, os falantes sempre lançam mão de sistemas sociolinguístico e gramatical, não necessariamente claros, rígidos e estruturados, mas orientados para

\footnotetext{
${ }^{12}$ No original: "Different kinds of people connect through the intermeshed discourses that constitute orders of discourse."

${ }^{13}$ No original: "A discourse is a configuration of knowledge and its habitual forms of expression, which represents a particular set of interests. Over time, for instance, institutions produce discourses - that is, their configurations of knowledge. Style is the configuration of all the semiotic features in a text in which, for example, language may relate to layout and visual images. Genres are forms of text or textual organization that arise out of particular social configurations or the particular relationships of the participants in an interaction. They reflect the purposes of the participants in a specific interaction. In an interview, for example, the interviewer wants something, the interviewee wants something else, and the genre of interview reflects this. Dialects may be region or age related. Voice is more individual and personal, including, of course, many discursive and generic factors."
} 
ações semióticas. Além disso, fazem parte dos Designs Disponíveis as experiências linguístico-discursivas dos envolvidos no Design que aparecem no momento/processo do Design e em sua continuação, o que NLG chama de contexto intertextual (FAIRCLOUGH, 1989 apud THE NEW LONDON GROUP, 1996) que conecta o texto com outro(s) texto(s) ou cadeias de textos.

É importante ressaltar que a construção de textos/contextos intertextuais não é a simples repetição dos Designs Disponíveis, ou seja, não é a simples repetição do que há disponível na língua para criar significados. Cada momento de significado envolve a transformação dos Designs Disponíveis em processos de representação e recontextualização através da leitura, escrita, audição e visão. Assim, o processo de Designing irá, mais ou menos, reproduzir/transformar dados conhecimentos, relações sociais e identidades dependendo das condições sociais sob as quais ocorra. Dessa forma, o conhecimento dado - Designs disponíveis - é transformado em novas construções e novas representações da realidade; as pessoas transformam suas relações umas com as outras e, nesse processo, transformam a si mesmas. Todas essas transformações de sujeitos, relações sociais e conhecimento tomam lugar no processo de Designing, mas reverberam no Redesigned em forma de produto. E levando em consideração o que foi dito neste parágrafo sobre o Designing, fica claro que ele assume um caráter de processo provisório ao transformar o uso de velhos materiais, ao (re)articular e (re)combinar recursos dados pelos Designs Disponíveis.

Ainda nessa esfera do Designing, o NLG deixa claro que interpreta as quatro habilidades linguísticas (ler, escrever, falar e ouvir) como atividades produtivas que acontecem sob o processo do Designing. Ouvintes e leitores se deparam com textos como Designs Disponíveis na língua e lançam mão de experiências próprias com outros Designs Disponíveis como recurso para criar novos significados a partir dos textos com os quais se deparam. Suas habilidades de escuta e leitura são uma produção (um Design) de textos baseados nas suas próprias experiências de vida e interesses, transformando, assim, em Redesigned os recursos recebidos através dos Designs Disponíveis.

O Redesigned, por sua vez, é o resultado do Designing. É um novo significado. Não é uma reinstanciação ou uma simples combinação de Designs Disponíveis, também não é uma simples reprodução/criatividade simples. Por isso que o Redesigned pode ser 
variadamente criativo ou reprodutivo em relação aos recursos para a criação de significados a partir dos Designs Disponíveis. Ele é cultural e historicamente conceituado tendo em vista as contribuições subjetivas dos sujeitos, e justamente por isso tem a sua unicidade com cada Redesigned sendo diferente de outro(s), daí sua unicidade faz com que cada Redesigned assuma a posição de um novo Design Disponível, de uma nova fonte de recurso para criação de significados.

Esse processo de criação de significados é, então, um processo cíclico no qual os criadores de significados, os sujeitos, refazem, reconstroem e renegociam suas identidades e intervêm ativamente no mundo saindo, ao final do processo, como sujeitos transformados.

Encerrada a tríade de criação de significados envolvendo os três elementos do Design, o NLG inicia a discussão sobre as dimensões do significado e da linguagem. Agora, alunos e professores precisam de uma linguagem envolta nos processos de significação, linguagem essa que o NLG chamou de metalinguagem, ou seja, uma linguagem para falar sobre a própria língua, imagens, textos e interações envolvendo a criação de significados.

Na proposta por um Projeto Internacional de Multiletramentos, um dos objetivos principais propostos no manifesto, a língua ocupa lugar central não apenas nas discussões, mas sobretudo no uso que se faz dela nas práticas de multiletramentos. Para tanto, o NLG propôs o desenvolvimento de uma gramática funcional educacionalmente acessível, i. e., uma metalinguagem que descreve significado em vários domínios: textual, visual, relações multimodais entre diferentes processos de criação de significados tão importantes para os textos midiáticos e de multimídia eletrônica. Assim, a metalinguagem através da gramática funcional deve passar a integrar o currículo das escolas juntamente com práticas críticas de análise da língua e outros sistemas semióticos.

Uma metalinguagem também precisa ser flexível, aberta e vista como um conjunto de ferramentas para trabalhar com atividades semióticas. Assim, professores e alunos podem escolher suas ferramentas e também construir suas próprias. Essa característica flexível da metalinguagem é de suma importância para as práticas educativas, pois os eventos semióticos em análise podem ser descritivos ou analíticos de 
naturezas incertas, provisórias, mutáveis, e relativos aos contextos de propósitos e análises. Além dessas características citadas, a metalinguagem deve ter como propósito primário identificar e explicar diferenças entre textos e relacioná-los aos contextos de cultura e situação sem nunca impor regras, padrões de correção ou privilegiar um discurso em detrimento de outro(s).

Conjuntamente à metalinguagem, como alerta o NLG, há as convenções associadas aos Designs. Por exemplo, no caso dos gêneros textuais, questões como definição e nomenclatura que recebem quanto a seu uso na sociedade são importantes para integrar a análise. Além disso, características dos gêneros textuais como a sociedade na qual circulam, instituições que os legitimam, suas relações com outros textos, etc. devem integrar a metalinguagem. E, para o caso dos discursos, o manifesto (THE NEW LONDON GROUP, 1996, p. 78, grifo dos autores, tradução nossa,) explica o seguinte:

O discurso é uma construção de algum aspecto da realidade a partir de um ponto de vista particular, um ângulo particular, em termos de interesses particulares. Como um substantivo abstrato, o discurso direciona atenção ao uso da língua como uma faceta da prática social que é modelada por - e modela - ordens do discurso da cultura, assim como dos sistemas de línguas (gramáticas). Como um substantivo contável (discursos no plural, ao invés de discurso em geral), ele direciona atenção para a diversidade de construções (representações), de vários domínios de vida e experiência associado com diferentes vozes, posições e interesses (subjetividades). Novamente, alguns discursos são claramente demarcados e possuem nomes convencionais na cultura (por exemplo, feminista, político-partidário, ou religioso), enquanto outros são mais difíceis de apontar. ${ }^{14}$

E, por fim, como último ponto do "o quê" da pedagogia dos multiletramentos, temos os elementos do Design que englobam o Design linguístico e o Design de outros modos de significação.

Uma das ideias centrais dos multiletramentos é a crescente complexidade e interrelação de modos de significação que se combinam em seis grandes áreas através de

\footnotetext{
${ }^{14}$ No original: "A discourse is a construction of some aspect of reality from a particular point of view, a particular angle, in terms of particular interests. As an abstract noun, discourse draws attention to use of language as a facet of social practice that is shaped by - and shapes - the orders of discourse of the culture, as well as language systems (grammars). As a count noun (discourses in the plural rather than discourse in general), it draws attention to the diversity of constructions (representations) of various domains of life and experience associated with different voices, positions, and interests (subjectivities). Here again, some discourses are clearly demarcated and have conventional names in the culture (for example, feminist, party-political, or religious discourses), whereas others are much more difficult to pinpoint."
} 
gramáticas funcionais: Designs linguístico, visual, auditivo, gestual, espacial e multimodal. Lembrando que o termo multimodal representa a integração das outras cinco gramáticas funcionais.

A metalinguagem usada para o Design linguístico tem a proposta de trabalhar com os recursos representacionais da língua. Essa metalinguagem não é uma categoria de habilidades mecânicas, como é, por exemplo, a gramática normativa tradicional. Pelo contrário, a noção de Design enfatiza o potencial produtivo e inovador da língua como um sistema de criação de significados. Essa é uma ação, uma descrição gerativa de língua como meios de representação. Essa deve ser a visão sobre a sociedade e os textos que circulam nela, pois, como lembra o NLG, essa visão integrará economias e sociedades do presente e do futuro, sendo também essencial para a produção de tipos particulares de subjetividade democrática e participatória. Esses elementos do Design linguístico ajudam a descrever os recursos representacionais que estão disponíveis, os vários significados que esses recursos assumirão quando usados em determinados contextos e o potencial inovador para reformar esses recursos em relação a intenções e objetivos sociais.

O NLG (1996, p. 79, tradução nossa) considera os seguintes exemplos para contextualizar os dizeres acima: "As taxas de morte por câncer de pulmão estão claramente associadas com o aumento do tabagismo" e "Fumar causa câncer." ${ }^{15}$. As duas sentenças podem ter o mesmo significado podendo ser mais ou menos específicas ou explícitas. Assim, a gramática proposta pelo manifesto observará algumas questões importantes: as sentenças são usadas em discursos diferentes (o primeiro exemplo pode ser um discurso das ciências sociais e o segundo pode ser um discurso de discussões de saúde pública); o usuário da língua deve ter uma série de escolhas comunicativas para fins específicos, incluindo escolhas não verbais que não são simplesmente estilo ou intenção do usuário da língua, mas estão conectadas a diferentes discursos de interesses e relações de poder.

\footnotetext{
${ }^{15}$ No original: "Lung cancer death rates are clearly associated with increased smoking," e "Smoking causes cancer."
} 
Além do Design linguístico, há também o Design para outros modos de significação. Todos os Designs são importantes e a união deles aumenta as potencialidades de criação de significados. Assim, o Design multimodal possui um papel importantíssimo ao unir todos os modos de significações (ou quase todos a depender do contexto): visual (imagens, formatos de tela, etc.), áudio (música, efeitos sonoros, etc.), gestual (linguagem corporal, etc.), espacial (espaços ambientais, espaços arquitetônicos, etc.). Por exemplo, imagens da mídia de massa relacionam o linguístico com o visual e com o gestual através de maneiras intrinsecamente bem desenhadas; nesse caso, apenas o linguístico não é suficiente. Revistas usam gramáticas visuais em suas capas e nos seus conteúdos a depender de questões socioculturais; a televisão e seus programas; uma visita ao shopping pode requerer uma leitura espacial de sua organização arquitetônica, além do linguístico e do visual requeridos para ler as luzes, telas e letreiros.

Num senso mais profundo, todo processo de criação de significado é multimodal. Todo texto escrito é também visualmente orientado; toda língua falada é um Design linguístico, mas também é um áudio Design com elementos gestuais da linguagem corporal ao mexermos braços e mãos, ao falar e ao modificarmos nossas expressões faciais. Além disso, há também um componente histórico que participa da composição de um texto, uma vez que cada sujeito/assunto/tema carrega sua historicidade. Nesse sentido é que o NLG enfatiza a importância de se trabalhar com os Designs (THE NEW LONDON GROUP, 1996, p. 81, tradução nossa):

O conceito de Design enfatiza as relações entre modos de significado recebidos (Designs Disponíveis), a transformação desses modos de significado em seus usos híbrido e intertextual (Designing) e o seu status subsequente (Redesigned). A metalinguagem da criação de significado se aplica a todas as etapas desse processo: como as pessoas são posicionadas pelos elementos dos modos de significados disponíveis (Designs Disponíveis), ainda como os autores de significados em alguns sentidos importantes assumem a responsabilidade de estar conscientemente no controle de suas transformações de significados (Designing), e como os efeitos de significar, a sedimentação de significar, se torna uma parte do processo social (Redesigned).$^{16}$

\footnotetext{
${ }^{16}$ No original: "The concept of Design emphasizes the relationships between received modes of meaning (Available Designs), the transformation of these modes of meaning in their hybrid and intertextual use (Designing), and their subsequent to-be-received status (The Redesigned). The metalanguage of meaningmaking applies to all aspects of this process: how people are positioned by the elements of available modes of meaning (Available Designs), yet how the authors of meanings in some important senses bear the responsibility of being consciously in control of their transformation of meanings (Designing), and how
} 
O percurso que vai dos Designs Disponíveis, passando pelo Designing e chegando ao Redesigned pode variar bastante. Os Designers (criadores de significados) podem reproduzir os Designs Disponíveis mais próximos ou mais distantes dos Redesigneds por exemplo, uma carta comercial pode ser produzida próxima de um modelo padrão, mas pode variar como uma carta pessoal; essa mesma carta comercial pode ser mais sistematizada, planejada e deliberada do que uma carta pessoal, pode apresentar uma linguagem mais especializada ou uma linguagem mais comum.

Outras características que acompanham o percurso do Design ao Redesigned são a hibridez e a intertextualidade. Esta se refere às complexas formas com as quais os significados são constituídos ao se relacionarem com outros textos, outros discursos, outras narrativas e outros modos de significação. Aquela se refere aos mecanismos de criatividade nos quais as pessoas hibridizam práticas e convenções estabelecidas com diferentes modos de significação.

À hibridez, se inclui também hibridização de formas estabelecidas de modos de significação e combinações multifacetadas de modos de significação, cruzando limites de convenções e criando novas convenções. Um exemplo disso, citado pelo NLG, é a pop music, que mescla elementos diversos de culturas diversas criando novos padrões de estilo musical. Quanto à intertextualidade, se inclui também a historicidade que o texto possui ao se conectar a cadeias de outros textos, se transformando e sendo transformado. Como exemplo, o NLG cita filmes e suas referências, pois muitas vezes um filme, ou uma cena dele, resgata algo de outro lugar e de outro tempo, criando cadeias de textos explícitas ou sutis para a interpretação do leitor/da audiência.

\subsubsection{O “como" da pedagogia dos multiletramentos}

the effects of meaning, the sedimentation of meaning, become a part of the social process (The Redesigned)." 
No subitem anterior, trabalhamos com o "o quê" da pedagogia dos multiletramentos e agora veremos o "como" dessa pedagogia. De acordo com o NLG, qualquer teoria pedagógica bem sucedida deve ser baseada no componente social e deve-se preocupar também com a natureza do ensino e da aprendizagem. Por isso, as propostas curriculares/reformas pedagógicas devem deixar claras suas visões de sociedade, ensino e aprendizagem e como essas reformas poderiam ser eficazes. Portanto, para o NLG, a visão de sociedade, ensino e aprendizagem é uma visão incorporada, situada e social. Ou seja, o conhecimento humano é desenvolvido inicialmente não como algo geral e abstrato, mas sim como embutido em contextos sociais, materiais e culturais. Além disso, o conhecimento humano é inicialmente desenvolvido como uma parte/parcela de interações colaborativas com outros de diversas habilidades, experiências e perspectivas juntos em uma comunidade específica, ou seja, uma comunidade de aprendizes engajados em práticas comuns centradas em um domínio específico do conhecimento social e historicamente constituído.

Dessa forma, a pedagogia dos multiletramentos é uma integração complexa de quatro fatores: Prática Situada (PS), baseada nas experiências dos aprendizes; Instrução Explícita (IE), na qual os aprendizes formatam uma metalinguagem do Design; Enquadramento Crítico (EC), que relaciona significados aos seus contextos e propósitos sociais; e a Prática Transformada (PT), na qual os aprendizes transferem e (re)criam Designs de significado de um contexto a outro. O NLG enfatiza que esses quatro fatores não são linearmente hierarquizados, nem são estágios; podem ocorrer simultaneamente com um ou outro predominando, mas sempre sendo revisitados em diferentes níveis.

O primeiro fator, Prática Situada, propõe experiências de imersão em comunidades de aprendizes engajados em versões autênticas de tais práticas. Para o NLG, o conhecimento humano é socioculturalmente situado e contextualizado em domínios e práticas específicos de conhecimento. Apesar disso, a PS não apresenta apenas pontos positivos, conforme elencado pelo NLG a seguir. Os aprendizes imersos em práticas situadas podem variar bastante um dos outros, tendo em vista que se leva em conta a experiência de cada aprendiz. Além disso, a PS não leva necessariamente ao controle consciente e à percepção do que o aprendiz sabe/faz, que é um objetivo central de muito do que é aprendido na escola. Também não necessariamente cria aprendizes e 
comunidades críticos em relação ao que está sendo aprendido e nem sempre leva o aprendiz a colocar o aprendizado em prática.

O NLG complementa a PS com os seguintes dizeres (THE NEW LONDON GROUP, 1996, p. 85, tradução nossa):

é a parte da pedagogia que é constituída pela imersão em práticas significativas dentro de uma comunidade de aprendizes que são capazes de desempenhar múltiplos e diferentes papéis baseados em seus conhecimentos e experiências. ${ }^{17}$

Na PS, destaca-se também a figura de um especialista em algum domínio do conhecimento, que atuará como guia dos aprendizes dentro de uma comunidade; esse especialista saberá recrutar os conhecimentos dos aprendizes e conhecimentos externos que venham da comunidade na qual estão inseridos. Além disso, a PS deve considerar as necessidades e identidades afetiva e sociocultural dos aprendizes e construir um ambiente que o aprendiz possa correr riscos e aprender com colegas e professores. Assim, a avaliação nesse aspecto não deve ser de julgamento, mas usada de forma desenvolvimental para guiar os aprendizes às experiências que eles precisam ter como membros de uma comunidade capazes de se valerem de uma gama completa de recursos.

O segundo fator, Instrução Explícita, não implica transmissão direta, drills, memorização por repetição, muito embora às vezes tenha essa conotação. Na verdade, inclui todas as intervenções que o professor, ou outro especialista, faz para ajudar nas atividades de aprendizagem que levam o aprendiz a focar nas características importantes de suas experiências e atividades dentro da comunidade de aprendizes, ajudando o aprendiz a ganhar informações explícitas que o ajudarão na prática organizada e guiada, recrutando e construindo em cima do que o aprendiz já sabe. Inclui também a colaboração entre professor e aprendiz, para que este último consiga desenvolver tarefas mais complexas do que conseguiria realizar sozinho, desenvolvendo consciência do que é ensinado e relacionando as atividades com outros aspectos do que está sendo ensinado.

\footnotetext{
${ }^{17}$ No original: "This is the part of pedagogy that is constituted by immersion in meaningful practices within a community of learners who are capable of playing multiple and different roles based on their backgrounds and experiences."
} 
Além das características acima, outra característica da IE é o uso de metalinguagens, linguagens de generalização reflexiva. No caso dos multiletramentos propostos no manifesto, os aprendizes desenvolvem uma metalinguagem que descreve tanto o "o quê" da pedagogia dos multiletramentos (processos e elementos do Design) quanto o “como" (PS, IE, EC e PT).

O terceiro fator, Enquadramento Crítico, tem o objetivo de ajudar os aprendizes a enquadrar seus domínios crescentes na prática, o entendimento e o controle conscientes em relação às relações histórico-sociais, culturais, políticas e ideológicas de sistemas particulares de conhecimento e prática social. No EC, o papel do professor é desnaturalizar o que os aprendizes sabem para que ajam criticamente sobre esse saber. Assim, os aprendizes ganham uma distância pessoal e teórica do que aprenderam para poderem criticamente se posicionar.

Para o quarto fator, Prática Transformada, o NLG propõe retornar à Prática Situada como uma reprática, mas de cunho reflexivo. Aqui, precisam ser desenvolvidas junto aos aprendizes novas práticas pautadas em seus objetivos e valores, para que consigam implementar os entendimentos adquiridos através da IE e do EC em práticas que os ajudem a revisar e aplicar o que aprenderam. É na PT que é oferecido um lugar para a avaliação situada e contextualizada dos aprendizes e do projeto de aprendizagem.

\subsection{O Projeto Internacional de Multiletramentos (PIM)}

Apresentamos até aqui a proposta da pedagogia dos multiletramentos através de um projeto que o NLG chamou de "Projeto Internacional de Multiletramentos" no qual o "o quê" e o "como" da pedagogia dos multiletramentos se juntam para preparar aprendizes para uma sociedade multifacetada, para o mundo do trabalho, e para espaços cívicos através de práticas situadas. Assim, o ensino e a aprendizagem em sala de aula, bem como o currículo escolar, devem dialogar com as experiências dos alunos e com a diversidade de seus discursos, que são influenciados e definidos pela diversidades (sub)cultural e linguística e de práticas que vêm junto dessa diversidade. As instruções 
explícitas ajudarão os alunos a desenvolverem as metalinguagens necessárias para lidar com os variados Designs que, por sua vez, serão ligados a diferentes propósitos culturais através dos enquadramentos críticos; e, por fim, as práticas transformadas envolverão a movimentação cultural de um contexto a outro.

A ideia de Design reconhece a existência de diferentes formas de Designs Disponíveis de significados localizados em diferentes contextos culturais. A metalinguagem dos multiletramentos descreve os Designs não como regras, mas como uma heurística apontada para uma variabilidade infinita de formas diferentes de criação de significados em relação a (sub)culturas ou camadas de identidade de um indivíduo. Ao mesmo tempo, o Designing restaura a agência humana e o dinamismo cultural ao processo de criação de significado. Todo e qualquer ato de significação se apropria de Designs Disponíveis e recria no processo de Designing, assim produzindo novo significado como Redesigned. Em uma economia de diversidade produtiva, em espaços cívicos que valorizam o pluralismo e no florescimento de mundos inter-relacionados, multifacetados, complementários e divergentes, os trabalhadores, cidadãos e membros de comunidades são idealmente criativos e responsáveis criadores de significados.

O processo de trabalhar com as diferenças e com as fronteiras que agora cada vez mais se cruzarão não será um processo fácil. Quanto a isso, o NLG esteve sempre ciente e para tanto serão necessárias habilidades para lidar com essas diferenças. Além disso, o NLG deixa claro que o manifesto não possui todas as respostas, tendo em vista seu caráter basicamente teórico, mas ele é justamente um chamamento para a discussão e o debate entre professores e pesquisadores interessados na questão e na proposta de (re)pensar currículos para a educação. Com isso, a intenção do manifesto é suplementar a pedagogia vigente caminhando para a implantação do Projeto Internacional de Multiletramentos, que receberá contribuições de diversos lados: pesquisadores, desenvolvedores de currículo, professores e comunidades, pois seu caráter é amplo e complexo e requer um diálogo extenso com vários setores para o desenvolvimento de uma pedagogia que faça a diferença. E, por fim, o manifesto é um ponto de início para o PIM, por isso acompanhará as mudanças que impactem a prática educacional. 


\section{$3(\operatorname{Re})$ Ler o manifesto hoje}

Após fazermos uma (re)leitura "tão minuciosa e atenta quanto possível" (RIBEIRO, op. cit.) do manifesto no tópico anterior, discutiremos neste tópico uma (re)leitura do manifesto hoje, em tempos e lugares diferentes daqueles em que se deu sua concepção.

As discussões sobre os multiletramentos ganharam o mundo e chegaram à América Latina, sobretudo ao Brasil. Esse percurso é, para nós, importante, pois as ideias iniciais sobre multiletramentos provêm, principalmente, de países anglófonos cujas realidades são diferentes dos países latinos e a recepção dessas ideias responde a questões locais, ou seja, não podemos simplesmente fazer uma adesão ao dito sem antes refletir a partir do nosso contexto. Ainda assim, esse percurso justifica/explica como as questões concernentes aos multiletramentos impactam escolas, materiais didáticopedagógicos, professores e alunos. Dito de outra forma, os estudos sobre multiletramentos impactam as discussões sobre o universo escolar, sobre leis e currículos que norteiam a produção de material didático, por exemplo, e a orientação do que e como trabalhar em sala de aula (currículo).

Então, enquanto em meados da década de 1990 estávamos iniciando aqui no Brasil as discussões sobre letramento como prática social, países anglófonos já estavam iniciando as discussões sobre multiletramentos, que, no nosso caso, só iniciam depois dos anos 2000, mais precisamente a partir da publicação das Orientações Curriculares Nacionais para o Ensino Médio - OCNEM (BRASIL, 2006) quando o termo multiletramentos aparece explicitamente no documento e no artigo Linguagem digital e interpretação: perspectivas epistemológicas (MONTE MÓR, 2007). Importante destacar também que, no sentido das OCNEM, os multiletramentos aparecem na parte de língua estrangeira (Inglês) e só posteriormente passam a ser pensados para língua materna.

Uma década após aparecer em pesquisas e documentos educacionais, os multiletramentos seguem relevantes no cenário educacional brasileiro. Em 2017, outra importante publicação: a primeira versão da BNCC (Base Nacional Comum Curricular). Nela, diferentemente das OCNEM de 2006, os multiletramentos estão agora também 
atrelados à língua materna. Essa última década foi, então, pujante para os multiletramentos no Brasil: projetos de pesquisa, cursos e disciplinas começaram a surgir no cenário brasileiro que está hoje repleto de artigos, ensaios, dissertações e teses nessa área (RIBEIRO, 2020, 2021; HISSA; SOUSA, 2020).

Vimos, então, mesmo brevemente, que são inegáveis a importância, a contribuição e o alcance do manifesto e sua pedagogia mesmo 25 anos após sua publicação (TILIO, 2021). No Brasil, podemos sentir seus efeitos em várias instâncias, que vão desde documentos oficiais, como a BNCC, até farta produção científica como livros, teses, dissertações, artigos, etc. (PINHEIRO, 2021; ROJO; MOURA, 2012; COSTA SILVA, 2016). Ribeiro (2021, p. 7), por exemplo, destaca a influência do manifesto sobre os estudos de letramentos e multimodalidade no Brasil ao afirmar que ele é "um dos principais documentos em que se inspira nossa Base Nacional Comum Curricular (BNCC), embora isso não esteja explícito e nem identificado no documento.”. Nessa mesma linha, Hissa e Sousa também afirmam:

\footnotetext{
Aqui no Brasil a relação entre a pedagogia dos multiletramentos e a BNCC é muita estreita. Há marcas enunciativas, escolhas lexicais e forma de organização didática dos componentes da BNCC que se assemelham muito com o texto do GNL, sobretudo o componente Língua Portuguesa, no que se refere aos campos de atuação social, as competências e habilidades. HISSA; SOUZA, 2020, p.567).
}

Contudo, (re)ler o manifesto, hoje, após 25 anos de sua publicação, exige uma postura crítica do leitor. É importante ressaltar que os próprios membros do NLG fizeram algumas críticas, em forma de preocupações, à época da escrita do texto do manifesto e de possíveis reverberações que o texto poderia gerar. É possível visualizar no manifesto preocupação com as políticas neoliberais e suas influências na dinâmica escolar e nos sujeitos - alunos e professores -; a possibilidade de o "como" da pedagogia dos multiletramentos não funcionar para todos os alunos; a dinâmica capitalista muitas vezes desigual e perversa do mundo do trabalho, um atravessamento do discurso da globalização, etc. No entanto, chama atenção o fato de haver, apesar das preocupações dos autores, um capitalismo embutido no texto do manifesto (PINHEIRO, 2016) que acaba norteando uma apresentação preocupante de educação para o mundo trabalho. Nesse sentido, pertinentes são as palavras de Alencar sobre esse ponto: 
Esta é apresentada numa perspectiva bastante vinculada ao modelo "neoliberal", visando atender exigências de um sistema que requer que os indivíduos se adequem às especificidades desse modelo econômico a fim de serem inseridos no mercado de trabalho. A proposta do GNL, em certa medida, sugere currículos que se restringem a atender as exigências de formação de trabalhadores para as novas demandas da economia globalizada, que requer um profissional cada vez mais flexível e qualificado, apto a desenvolver múltiplas funções, sem destacar as implicações sociais e políticas das exigências desse modelo e sem refletir sobre a necessidade de formação crítica dos trabalhadores para que possam protagonizar uma possível transformação social. Falta ao debate desses autores uma proposta de resistência e superação das limitações impostas aos trabalhadores, como propunha Paulo Freire em todo o seu trabalho sobre a "alfabetização crítica". (ALENCAR, 2015, p.138).

(Re)Ler, ainda, o manifesto na nossa realidade brasileira latino-americana nos faz pensar sobre sua aplicação aqui. Um manifesto escrito há tanto tempo por pesquisadores de países anglófonos desenvolvidos poderia ser aplicado tal qual à nossa realidade? Toda a gama tecnológica prevista pelo manifesto como vindoura, de fato nos chegou aqui? Não é o que mostra a realidade das escolas, sobretudo públicas, que há pouco tempo enfrentavam um ensino remoto em decorrência da pandemia do novo coronavírus.

É impossível negar a importância do manifesto, mas é impossível replicá-lo tal qual está escrito sem antes fazermos um exame crítico dele. São muitas as questões que suscitam a partir da (re)leitura do manifesto, assim como também são muitas as críticas. Não temos a intenção de esgotar as questões e as críticas, pois cada (re)leitura pode suscitar novos insights.

\section{Para (não) concluir}

Vimos, de forma minuciosa e atenta, o manifesto do Grupo de Nova Londres e sua pedagogia dos multiletramentos que mesmo após 25 anos de sua concepção figuram ainda relevantes hoje em dia, prova disso sua influência na educação brasileira através de documentos norteadores, tais como as OCNEM e a BNCC. Contudo, (re)ler esse manifesto após tanto tempo e em lugares diferentes dos quais ele foi pensado, exige de nós uma postura crítica. 
Defendemos, então, a necessidade de sempre olhar para os multiletramentos e seu texto seminal - o manifesto - como apontam Allan Luke, um dos membros do NLG, numa entrevista concedida a Antero Garcia e Robyn Seglem (2018), e Cope e Kalantzis (2019) quando revisitam o manifesto. E que esse olhar, devemos lembrar, leve em consideração a realidade na qual estamos inseridos, que dificilmente será a mesma na qual o manifesto foi escrito, dada a multiplicidade de realidades socioeconômicas e culturais existentes.

\section{Referências}

ALENCAR, M. C. M. Breve panorama dos estudos de letramento(s) no Brasil - dos alfabetismos aos multiletramentos. UNILETRAS, Ponta Grossa, v. 37, n. 1, p. 123-140, jan/jun. 2015 .

BRASIL. Ministério da Educação. Orientações curriculares para o ensino médio. 2006.

CAZDEN et al. Uma pedagogia dos multiletramentos. Desenhando futuros sociais. (Orgs. Ana Elisa Ribeiro e Hércules Tolêdo Corrêa. Trad. Adriana Alves Pinto et al.). Belo Horizonte: LED, 2021.

COSTA SILVA, T. R B. Pedagogia dos multiletramentos: principais proposições metodológicas e pesquisas no âmbito nacional. Letras, Santa Maria, v. 26, n. 52, p. 11-23, jan./jun. 2016.

COPE, B.; KALANTZIS, M.; PINHEIRO, P. Letramentos. Editora da Unicamp, 2020.

COPE, B.; KALANTZIS, M. Literacies. Australia: Cambridge University Press, 2012.

. "Multiliteracies": New Literacies, New Learning, Pedagogies: An International Journal, v. 4, n. 3, p. 164-195, 2009.

GRUPO NOVA LONDRES. Uma Pedagogia dos Multiletramentos: Projetando Futuros

Sociais. Tradução de Deise Nancy de Morais, Gabriela Claudino Grande, Rafaela Salemme Bolsarin Biazotti, Roziane Keila Grando. Revista Linguagem em Foco v. 13, n. 2, 2021. p. 101-145. 
HISSA, D. L. A.; SOUSA, N. O. A Pedagogia dos Multiletramentos e a BNCC de Língua Portuguesa: diálogos entre textos. Revista (Con)Textos Linguísticos, v. 14, n. 29, p. 565$583,2020$.

LUKE, A. Looking at the Next 20 Years of Multiliteracies: A Discussion with Allan Luke. [Entrevista concedida a] GARCIA, A; SEGLEM, R. Theory Into Practice, v. 57, issue 1, p. 72-78, 2018.

MONTE MÓR, W. Linguagem digital e interpretação: perspectivas epistemológicas. Trabalhos em Linguística Aplicada, n. 46(1), p. 31 - 44, Jan./Jun. 2007.

PINHEIRO, P. Sobre o manifesto "A pedagogy of Multiliteracies: Designing Social Futures" - 20 anos depois. Trabalhos em Linguística Aplicada, n. 55.2, p. 525-530, 2016.

PINHEIRO, P. A Pedagogia dos multiletramentos 25 anos depois: algumas (re)considerações. Revista Linguagem em Foco, v.13, n. 2, p. 11-19, 2021.

RIBEIRO, A. E. Que futuros redesenhamos? Uma releitura do manifesto da Pedagogia dos Multiletramentos e seus ecos no Brasil para o século XXI. Diálogo das Letras, v. 9, p. 1-19, 2020.

E. Apresentação. In: CAZDEN et al. Uma pedagogia dos multiletramentos. Desenhando futuros sociais. (Orgs. Ana Elisa Ribeiro e Hércules Tolêdo Corrêa. Trad. Adriana Alves Pinto et al.). Belo Horizonte: LED, 2021.

ROJO, R; MOURA, E. Multiletramentos na escola. São Paulo: Parábola, 2012. THE NEW LONDON GROUP. A Pedagogy of Multiliteracies: Designing Social Futures. Harvard Educational Review, v. 66, n. 1, spring 1996, p. 6o-92.

TILIO, Rogério. (Re)interpretando e implementando criticamente a Pedagogia dos Multiletramentos. Revista Linguagem em Foco, v. 13, n. 2, 2021. p. 33-42.

Recebido em 30/o7/2021. Aprovado em 08/12/2021. 